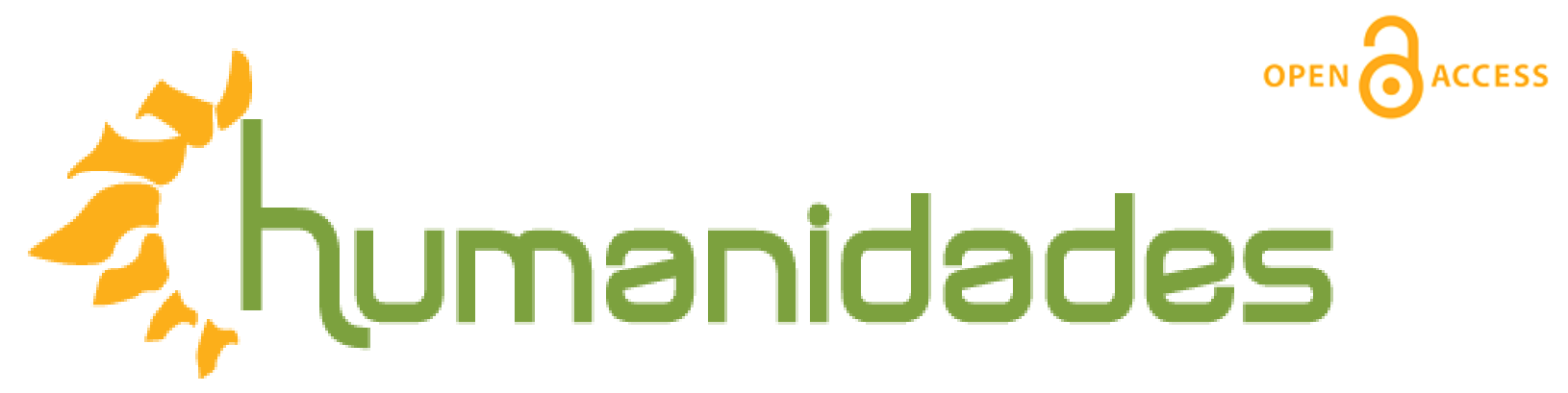

Revista de la Escuela de Estudios Generales, Universidad de Costa Rica

Julio-diciembre, 2016 • Volumen 6, número 2 • EISSN 2215-3934•pp. 1-20

Recibido: 17-Enero-2016 Aceptado: 22-Abril-2016

\title{
Pico e’ lapa: Filosofía de una ironía trágica. Una relectura aristotélica
}

DOI: http://dx.doi.org/10.15517/h.v6i2.26748

\section{Andrés Solano Fallas}

Docente en la Universidad de Costa Rica, Sede Regional del Pacífico, y en la Universidad Estatal a Distancia, Escuela de Ciencias de la Educación.

Correo electrónico: sadsunsea@gmail.com

Todos los derechos reservados. Universidad de Costa Rica. Esta revista se encuentra licenciada con Creative Commons. Reconocimiento-NoComercial-SinObraDerivada 3.0 Costa Rica.

Correo electrónico: humanidades@ucr.ac.cr / Sitio web: http://revistas.ucr.ac.cr/index.php/humanidades 


\title{
Pico e’ lapa: Filosofía de una ironía trágica. Una relectura aristotélica
}

\section{Resumen}

En este artículo se realiza una relectura aristotélica sobre cuatro temas que, enmarcados en el concepto de ironía, aparecen en la novela costarricense Los Hijos del Diablo. Pico e' Lapa, el último de Minor Herrera-Valenciano. Se define qué es ironía de acuerdo con Aristóteles y posteriormente se analizan los temas seleccionados como ejemplos de esta figura, estos son: la decisión de un padre, perder el miedo, sobre las amistades peligrosas y la ley del silencio (justicia). Cada uno responde a asuntos propiamente de la Ética a Nicómaco (la decisión, el miedo, la amistad, la justicia); en lugar de tratarlos individualmente, se les engloba como ejemplos irónicos de la vida de Pico e’ Lapa.
Palabras claves:

Filosofía, literatura, ética, violencia, problema social.

\section{Pico e' lapa: Philosophy of a Tragic Irony. An Aristotelian Reading}

\begin{abstract}
This paper consist in an Aristotelian reading of four topics, circumscribed within the concept of irony, which appears in a Costa Rican novel Los Hijos del Diablo. Pico e' Lapa, el último [The Sons of the Devil. Pico e' lapa, the last one] of Minor Herrera-Valenciano. A brief overview is provided. Then, it will begin on what irony is, according to Aristotle, in order to analyze how the four selected topics are examples of irony. The topics are the following: the decision of a father, to lose fear, on dangerous friendships, and the Silence Law ("Justice"). Each of these responds to Nicomachean Ethics actual topics (decision, fear, friendship, and justice). Instead of studying them individually, they will be encompass as ironic examples of Pico e' Lapa's life.
\end{abstract}

\author{
Keywords: \\ Philosophy, literature, \\ ethics, violence, \\ social problems.
}


Este artículo explora, desde una perspectiva aristotélica, la ironía en la vida del notorio e infame exconvicto costarricense de los años setenta Luis Gerardo Quesada Fernández, mejor conocido como Pico e' lapa, miembro de la temible banda carcelaria de la Antigua Penitenciaría Central de Costa Rica, Los Hijos del Diablo. Para estos fines, se toma como texto base, y fundamental, la biografía novelada que Minor Herrera-Valenciano realizó de Pico e' lapa: Los Hijos del Diablo. Pico e' Lapa, el último. Así pues, se ofrece una breve reseña para contextualizar al lector.

Posteriormente, como punto angular, se expone una concepción de la ironía, vista desde El Estagirita, la cual permitirá ahondar en cuatro aspectos irónicos que marcaron su vida. En primer lugar, se tiene una decisión paternal que pretendía ser beneficiosa. En segundo lugar, la pérdida del miedo que tuvo por objetivo asegurar la sobrevivencia del protagonista, pero que lo transformó. En tercer lugar, el tema de las amistades peligrosas, cómo estas influyen en la manera de ser. En cuarto lugar, está el tema de la justicia que se pretendía ejercer bajo la ley del silencio. 
La biografía novelada narra los hechos que condujeron a que Luis Breve reseña

Gerardo Quesada Fernández, conocido como Pico e' lapa por el recuerdo colectivo costarricense, conformara la temida banda Los Hijos del Diablo, durante los años setenta, en la antigua Penitenciaria Central. El personaje cuenta su versión de los hechos en relación con la banda, tanto los motivos para conformarla como su final. Así mismo, aporta una "radiografía" sociocriminal del brutal ambiente carcelario costarricense. Si bien el punto de interés es la banda, cabe señalar que el texto hace un recorrido a través del recuerdo del mismo personaje, de su infancia y dura adolescencia, hasta que ingresa por primera vez al centro penitenciario; también de las terribles condiciones que antecedieron al nacimiento de Los Hijos del Diablo, para culminar en un arrepentimiento. De esta manera, el autor busca ilustrar las condiciones socioculturales y jurídicopenitenciarias que, de algún modo, incidieron en la irónica trágica vida del personaje.

La ironía puede ser entendida como una forma discursiva en la que se pretende dar un mensaje, de manera oculta o entre líneas, para evitar expresarlo directamente; ya sea porque: se busca causar mayor impacto en el receptor; lo "fuerte" del mensaje hace que sea más apropiado entregarlo de una manera más amena; se quiere realizar una burla más "sutil"; o bien, se busca que el receptor genere una reflexión crítica en el momento de procesar el mensaje. 
La vida de Pico e' lapa, narrada por Herrera-Valenciano, a través del mismo personaje, podría entenderse, en una primera aproximación, de acuerdo con esa ironía discursiva. Es decir, como una narración de vida en la que el personaje protagónico, por medio de un largo recorrido, busca o pretende que el lector comprenda -sin que esto signifique justificar-su arrepentimiento.

Desde Aristóteles, el tema de la ironía resulta interesante, por ende, lo es también comprender la vida de Pico e' lapa desde esta perspectiva. Para este filósofo griego, la ironía no se detiene ni se agota meramente en el plano discurso. Es muy sintomático que cuando El Estagirita se refiere a este tópico, no se haya limitado únicamente a su tratado de la Retórica, sino que volviera sobre ello en uno de sus libros de ética, a saber, la Ética a Nicómaco. En este libro incluye la ironía, o propiamente lo irónico, como un modo de ser de la persona, lo cual quiere decir que esta figura tiene que ver con una actitud existencial (Álvarez-Sanagustín, 1986); con una manera de desenvolverse y desarrollarse en la cotidianidad.

Desde esta perspectiva aristotélica, Pico e' lapa no solamente narra con ironía su vida, al exponer diversas situaciones que lo marcaron y que lo condujeron finalmente al arrepentimiento, sino que su vida misma es un ejemplo de una ironía, de una manera de ser que lo 
conformó, o mejor, como dice el mismo personaje, lo deformó (Herrera-Valenciano, 2015).

Un primer punto que permite apreciar el inicio de su ironía trágica radica en lo que parecía ser, en su momento, la mejor decisión, según las condiciones de vida de los personajes. Pico e' lapa cuenta que su padre, al enviudar, prefirió que sus hijos vivieran con los abuelos, ya que, en principio, era mejor que permanecieran cuidados y vigilados, en vez de estar solos en la casa.

Esta decisión tuvo por objetivo brindarles un mejor hogar. Es importante notar que no se trata de una mejor casa, por cuanto que casa ya tenían, sino un hogar; es decir, un entramado de relaciones sanguíneo-políticas en la que los miembros mayores darían no solamente un techo, comida y un cuido, sino un punto de pertenencia a una familia. Empero, el foco de afecto fue lo que menos encontraron los niños, puesto que sufrieron abusos físicos y mentales por parte de su abuelo, quien se mantuvo impune, tanto por ser el dueño de la casa de San José, como por ser el patriarca autoritario -dada la ideología sexista (Amorós, 1991) de la época que sometía a la mujer al dominio del hombre-; no encontró a nadie que lo enfrentara. Por un lado, estaría la abuela y las nietas (las hermanas de Pico e' lapa) quienes eran sumisas y, por otro lado, el padre del protagonista que de algún modo avalaba el trato abusivo, al no inmiscuirse. 
De este modo, irónicamente sacaron a Pico e' lapa de un hogar monoparental (cuando su padre enviudó) y lo trasladaron a una casa que albergaba situaciones de abuso. Esto lo condujo a tomar la decisión de irse a las calles y a rodearse de malas juntas. Resulta difícil, si es que no imposible, responsabilizar a Pico e' lapa por haber preferido las calles y, lamentablemente, las malas influencias. La decisión de su padre fue la puerta introductoria a su trágica vida, cuando la intención era que contara con mejores condiciones.

Podría considerarse, siguiendo la línea argumentativa que hace Herrera-Valenciano, que esta decisión es prácticamente el primer peldaño de la antesala al Infierno (la Penitenciaría Central), puesto que el personaje empieza a moldear su carácter. En él empieza a crecer el resentimiento hacia su padre y el odio a su abuelo -que casi lo llevó a matarlo--. Aunado a esto, surge la idea de que no siempre se puede confiar en la misma sangre. Todo lo anterior (y más,) a partir de una decisión "beneficiosa".

Otro punto que permite ver cómo la ironía es modeladora del carácter reside en el hecho de que el personaje pierde el miedo al Infierno. Según Aristóteles, el miedo se entiende como expectación de un mal, lo cual implica que esta pasión no debe ser concebida como una cualidad negativa de la persona, ya que el miedo es un estado

\section{Perder el miedo al Infierno}


innegable a todo ser humano; y por ser una pasión, significa que mueve a la persona a actuar o no actuar.

Desde esta perspectiva, el miedo resulta útil, en tanto puede permitir que una persona (temerosa de alguna situación, persona o asunto) se comporte de cierta manera. En otras palabras, el miedo puede fungir como un mecanismo de autocontrol o principio heurístico que guía a la persona en su cotidianidad, al tener que tomar decisiones. Debe tomarse en cuenta que en Aristóteles las pasiones no acaecen por elección deliberada; no obstante, pueden ser un freno o un impulso cuando es necesario tomar una decisión.

Herrera-Valenciano menciona que, en su primer arresto, Pico e' lapa le tenía miedo a la cárcel; para ser concretos a la Penitenciaría Central o, como el personaje la define, al Infierno. El miedo que sentía en La Peni, de algún modo, lo contuvo por un breve tiempo. Así pues, se puede decir que quien entró por primera vez fue Luis Gerardo Quesada Fernández y no Pico e' lapa.

El personaje tenía claro que adentro se encontraría un ambiente de "sálvese quien pueda" y que, si no se es "duro", terminaría muerto o siendo la mujer de alguien más. El miedo que le tenía al lugar, de alguna forma, logró cohibirlo por un tiempo. Sin embargo, y aquí es donde aparece lo irónico, cuando finalmente pierde el temor, se 
transforma en Pico e' lapa. En palabras del protagonista, después de haber matado al primer recluso:

En ese instante ocurrió en mí uno de los cambios de los que ahora me arrepiento. En ese momento le perdí el miedo a la cárcel y todo lo que esta representaba para muchos, porque noté que para sobrevivir en ese ambiente tan terrible lo único necesario era plantearse duro, con toda la hombría que se tuviera, hablar fuerte, casi gritando, y tener un cuerpo fuerte e impotente como el que tenía en esos días (Herrera-Valenciano, 2015, p. 42).

La pérdida del miedo al Infierno abrió otra puerta más en su vida, la cual marcó en definitiva su manera de ser. Por un lado, causó que lo renombraran Pico e' lapa; y, por otro lado, permitió que, años después, se convirtiera en un Hijo del Diablo. La ironía en dicha situación yace en que esta pérdida se debió a un motivo de sobrevivencia, ante las condiciones salvajes y corruptas de la cárcel. Pico e' lapa tenía dos opciones: mantener su miedo, pero atenerse a ser asesinado o prostituido/violado; o bien, eliminar tal miedo y sobrevivir. La escogencia de la segunda opción lo hizo fuerte y duro, pero brutal; por ende, una persona sin ningún tipo de sujeción. Irónicamente, esto propició que posteriormente formara parte de Los Hijos del Diablo. 
Así las cosas, esta ironía, que buscaba la sobrevivencia, lo convirtió en un terrible y temido criminal en el ámbito costarricense. De hecho, durante las tres ocasiones que logró escapar del Infierno, en las cuales vivió con su pareja Sara, continuó delinquiendo. Lo anterior permite considerar que la pérdida del miedo modificó su carácter y su manera de ser, dentro y fuera de la cárcel.

Un tercer punto, que ejemplifica cómo la ironía es modificador del ser, son las amistades. En el Libro VIII de la Ética a Nicómaco, Aristóteles expresa que la amistad es lo más necesario para la vida y que sin amigos nadie querría vivir, aunque se estuviera rodeado de bienes. La amistad, entonces, es un bien preciado al que toda persona debe aspirar; puesto que, en primer lugar, ofrece refugio ante cualquier tipo de necesidad. Los amigos generan confianza en las personas; a pesar de que todo vaya mal, se considera que existe un lugar al cual se puede acudir, es decir, se trata de un único sitio que jamás desaparecerá, aun cuando se haya perdido todo lo demás.

En segundo lugar, la amistad les ofrece a los jóvenes resguardo ante los errores y a los viejos les brinda asistencia. El amigo, por lo tanto, no solo estará presente cuando todo salga mal, sino que también se manifestará como una ayuda: ayuda que estará condicionada por el amigo. En otras palabras, un joven requiere consejos, dada su falta 
de experiencia, y un viejo precisa de asistencia, cuando la vejez empiece a languidecer a la persona.

En tercer lugar, la amistad permite que los amigos estén "más capacitados para pensar y actuar", ya que no es lo mismo enfrentarse al mundo solo, y sin nadie a quien recurrir, que hacerlo en compañía de alguien en quien se confíe. Este último punto no garantiza que se tome la mejor decisión, ni que siempre se reflexione adecuadamente, pero garantiza que la persona no se sienta sola o que se perciba abandonada.

Con Pico e' lapa se puede observar, a través del recorrido realizado por el personaje, que estrictamente careció de una verdadera amistad, en el sentido aristotélico. En esa línea, jamás contó con un refugio. Si bien el personaje tenía lugares a los cuales podía acudir, cuando se escapaba para esconderse de la policía, estos no le ofrecían protección. Por el contrario, solo eran un paradero para descansar y luego seguir delinquiendo.

Las amistades que tenía fuera del Infierno no lo guardaban del error, antes bien, lo alentaban, al proporcionarle armas y un escondite, y al no cuestionarle sus acciones. En razón de esto, se pierde el tercer aspecto de la amistad: sus amigos no lo capacitaron para pensar y actuar, en ninguna de las tres ocasiones que escapó de La Peni. Cabe mencionar que lo anterior no se limita (ni se agota) a las amistades 
que tuvo después de haber ingresado a la cárcel por primera vez; también aplica para las que surgieron antes de ser arrestado, debido a que prácticamente lo condujeron a peleas y problemas.

A lo sumo podría decirse, de acuerdo con la narración presentada por Herrera-Valenciano, que lo más cercano que Pico e' lapa tuvo por amistad, cuando escapaba, fue su compañera sentimental Sara. Esta mujer le ofreció su amor y compañía, como un punto al cual podía recurrir; y, aunque Sara fracasó en su intento por sacarlo de la vida criminal, al menos lo intentó. Podría considerarse, entonces, que Sara representa un prototipo de amistad; el cual, por causa de la transformación sufrida, Pico e' lapa no pudo valorar.

No hay duda de que adentro del Infierno se encontraba un ambiente sin amistad, o bien, de falsas amistades; en palabras de El Estagirita, de amistades por accidente, "porque uno es amado no por lo que es, sino por lo que procura, ya sea utilidad, ya placer. Por eso tales amistades son fáciles de disolver" (Aristóteles, 1985, p. 327). En el Infierno había que estar "ojo al Cristo y espalda a la pared" (Herrera-Valenciano, 2015, p. 39), puesto que, quien dejara de ser útil o se convirtiera en una labilidad, moría; sin importar los años que tuvieran de conocerse y las experiencias hayan compartido los amigos. 
Expresado lo anterior, el aspecto irónico de las amistades del personaje principal consiste en que estas influyeron negativamente en su manera de ser, en lugar de ser una ayuda positiva. Existe un adagio popular que reza "Dime con quién andas y te diré quién eres"; en el caso de Pico e' lapa, sus amistades, tanto antes como después de ingresar a La Peni, influyeron negativamente en su manera de comportarse. Antes del ingreso, fue amigo de Macho, quien lo incitó a que matara a otro hombre en un bar, al decirle al oído "póngase vivo, porque ese mae lo va a matar a usted" (Herrera-Valenciano, 2015, p. 21). Más que una ayuda, causó un impacto vital: en vez de alejarlo de una situación problemática, lo introdujo en esta.

En relación con las amistades que tenía fuera de la cárcel, cuando se escapaba, estas promovían sus malos hábitos. En definitiva, dentro de La Peni, se puede comprender -aunque quizá no justificar- que Pico e' lapa procurara mantenerse cerca de los más brutales del pabellón norte, como un mecanismo de sobrevivencia. Sin embargo, esta intención por crear una zona de relativo confort lo llevó a ser parte de la temible banda Los Hijos del Diablo.

Pues bien, resulta conveniente resaltar lo perjudicial que fueron estas amistades. No era suficiente matar a quien representara un obstáculo para este grupo, sino que debían torturarlo de la manera más salvaje y carnicera posible. Por lo tanto, lo irónico de sus amistades radica 
en el hecho de que estas, en vez de ser un apoyo, fueron una suerte de martillo que diariamente batía sobre el personaje, al punto de llevarlo a lo hondo y no poderlo sacar.

Un último punto, en el cual se puede identificar la ironía, es el momento en que se decide imponer reglas y ordenamientos, La ley del silencio: Justicia conocidos en el Infierno como "la ley del silencio"; término acuñado por Caballón en una pared, con la sangre de Canalete, después de haber sido asesinado violentamente (Herrera-Valenciano, 2015). Este código, de acuerdo con el personaje, buscaba justicia.

Para Aristóteles, la justicia “es la única, entre las virtudes, que parece referirse al bien ajeno, porque afecta a los otros; hace lo que conviene a otro" (1985, p. 241). Lo anterior quiere decir que quien ejerce la justicia no lo hace con aras de obtener provecho para sí mismo, ni mucho menos para recibir honores. En todo lo que se haga, es preciso tener a los otros como referentes y remitentes de las acciones.

Como se puede notar, la justicia aristotélica es una justicia relativa al congénere, por lo que, las acciones que se realicen deberán variar, según la persona en cuestión. Más adelante, El Estagirita comenta que la justicia no consiste meramente en realizar actos que se consideren o sean justos; en el fondo, esta representa una manera de 
ser, en la cual nadie debe verse forzado a llevar a cabo algo justo, antes bien, que sea parte de sí.

Desde esta perspectiva aristotélica, la justicia ejercida por Pico e' lapa y su banda Los Hijos del Diablo buscaba hacerle un bien a aquellos hombres indefensos de La Peni (Herrera-Valenciano, 2015) y castigar a quienes ingresaran a la cárcel por violar a un niño (Herrera-Valenciano, 2015). Así mismo, buscaba una mejora con respecto a las condiciones infrahumanas en las que estaban (Herrera-Valenciano, 2015).

En el primer caso, Pico e' lapa estaba cansado de los múltiples abusos que los "caneros de alta sentencia" cometían sobre los nuevos ingresos, además, del despojo de sus pertenencias y la esclavización de estos; eran víctimas de violaciones sexuales. Ante esta situación, la nueva ley pretendía poner fin a estos atropellos. De alguna manera, podría considerarse que Pico e' lapa y su banda ejercían una justicia muy cercana a la acepción aristotélica, puesto que sus acciones se llevaban a cabo -de acuerdo con ellos- en beneficio del otro victimizado. En relación con las violaciones sexuales, concretamente el personaje dice: “Así fue como a más de uno de los recién llegados se les ayudó a mantener intacta su hombría y, en ese sentido, pensábamos que nuestra labor se justificaba" (Herrera-Valenciano, 2015, p. 93). 
Sin embargo, esta justicia genera dudas, por causa de la manera brutal en que era ejercida y la intención de fondo. Según El Estagirita, bajo ninguna circunstancia podría considerarse hacer un bien, mediante el frío y crudo asesinato de otra persona. La justicia no es un asunto de resultados; no se trata solo de cuántos hombres se vieron beneficiados por esta ley del silencio, sino también de la manera en que se ejerció. Irónicamente, la justicia empleada por Pico e' lapa fomentó su crueldad y brutalidad, ya que, con el fin de implementar justicia, se permitía a sí mismo cometer actos bárbaros.

Aunado a lo anterior, es muy revelador que esta ley, si bien pretendía poner límites a los altos caneros, era un medio para ejercer el control en toda la Penitenciaría Central. Así lo deja ver Pico e' lapa cuando dice que la razón para unirse a Caballón, y formar Los Hijos del Diablo, fue tener más presencia de la que ya gozaba (HerreraValenciano, 2015). De esta manera, la pretendida justicia que buscaba no fue más que una excusa para imponer terror, puesto que una de las condiciones fue la siguiente:

Lo que acordamos fue que a todos aquellos a los íbamos a matar no debíamos tenerles misericordia ni debíamos propinarles una muerte rápida, sino todo lo contrario, a nuestra [sic] víctimas debíamos propinarles una muerte lenta y espantosamente dolorosa, que durara, ojalá, horas o días (Herrera-Valenciano, 2015, pp. 81-82). 
Se puede observar que, irónicamente, lo que procuraba generar justicia fue más un medio que reconoció y promovió sus actos violentos. Quizá la ley del silencio trajo consigo actos justos -o cercanamente justos-, pero no modificó su manera de ser, ni mucho menos la atenuó.

Esto es aún más sintomático cuando se toman en consideración los otros dos casos, a saber: hacer justicia por los niños que hubiesen sido violados y demandar mejores condiciones humanas. En la narración de Pico e' lapa no se mencionan nuevamente estos otros fines que tenía la ley del silencio. Tampoco se alude a que él, su banda o ambos, hayan ajusticiado a un preso culpable de violar a un infante. Antes bien, este motivo parece haber sido un autoengaño para justificar sus actos bárbaros.

Sobre la demanda de mejores condiciones, parece que ocurrió lo mismo, puesto que tampoco se mencionan datos al respecto; en cambio, se encrudece bestialmente la "selva" penitenciaria. De ahí que, irónicamente, la justicia de la ley del silencio resultó ser más bien un modo idóneo para llevar a cabo actos sanguinarios, en vez de ejercer realmente la justicia; es decir, buscar el bien de los demás reclusos. 
A partir de lo expuesto en este trabajo, se puede apreciar que la ironía no fue

\section{Conclusión} un mero recurso discursivo con el cual el personaje busca el arrepentimiento, por medio del autor del libro, sino una actitud existencial que envuelve la manera de ser de Pico e' lapa. Así pues, su vida es un claro ejemplo de que la ironía es un asunto ético, por cuanto tiene que ver con el carácter de cada persona. Por lo anterior, se trata de una filosofía que permite comprender cómo ciertos momentos, situaciones, decisiones, entre otros, tuvieron, en principio, una intención beneficiosa, o bien pretendían resolver un problema inmediato; sin embargo, dicha intención terminó por desviarse, incluso, logró marcar la vida de un hombre de forma trágica. 
Pico e’ lapa: Filosofía de una ironía trágica...

Álvarez-Sanagustín, A. (1986). Enunciación e ironía. Archivum, 36, Referencias 77-87.

Amorós, C. (1991). Hacía una Crítica de la Razón Patriarcal. Barcelona: Anthropos.

Aristóteles. (1985). Ética Nicomáquea/Ética Eudemia. Madrid: Gredos.

Aristóteles. (1999). Retórica. Madrid: Gredos.

Brun, J. (1988). Aristóteles y el Liceo. Barcelona: Paidós.

Contreras, S. (2012). La justicia en Aristóteles. Una revisión de las ideas fundamentales de Ethica Nicomachea. Ágora, 14, 63-80.

Domínguez, V. (2003). El miedo en Aristóteles. Psicothema, 15(4), 662-666.

Flores-Vásquez, A. (2012). El фóßos en Aristóteles: Una aliciente de

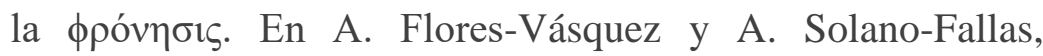
Memoria del Seminario de graduación sobre los conceptos del placer, el miedo y la ira en la Ética nicomáquea de Aristóteles. (Licenciatura en Filosofía). Universidad de Costa Rica, San José, Costa Rica.

Herrera-Valenciano, M. (2015). Los Hijos del Diablo. Pico e’ Lapa, el último. San José, Costa Rica: Atabal. 
Hutchinson, D. S. (1995). Ethics. En J. Barnes (ed.), The Cambridge Companion to Aristotle. Cambridge: Cambridge University Press.

Reale, G. (1992). Introducción a Aristóteles. Barcelona: Herder.

\section{¿Cómo citar este artículo?}

Solano, A. (Julio-diciembre, 2016). Pico e' lapa: Filosofía de una ironía trágica. Una relectura aristotélica. Revista humanidades, 6(2), 1-20. doi: dx.doi.org/10.15517/h.v6i2.26748 